\title{
Mixing and its effects on biogeochemistry in the persistently stratified, deep, tropical Lake Matano, Indonesia
}

\author{
Sergei Katsev, ${ }^{\mathrm{a}, *}$ Sean A. Crowe, ${ }^{\mathrm{b}, 1}$ Alfonso Mucci, ${ }^{\mathrm{b}}$ Bjørn Sundby, ${ }^{\mathrm{b}, \mathrm{c}}$ Sulung Nomosatryo, ${ }^{\mathrm{d}}$ \\ G. Douglas Haffner, ${ }^{e}$ and David A. Fowlef

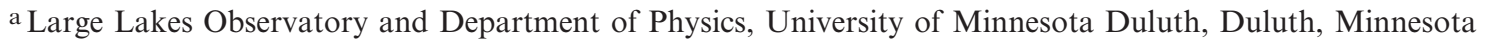 \\ b Department of Earth and Planetary Sciences, McGill University, and Geochemistry and Geodynamics Research Center (GEOTOP- \\ McGill-UQAM), Montréal, Québec, Canada \\ ${ }^{\mathrm{c}}$ Institut des sciences de la mer de Rimouski (ISMER), Université du Québec à Rimouski, Rimouski, Québec, Canada \\ d Research Center for Limnology, Indonesian Institute of Sciences (LIPI), Cibinong-Bogor, Indonesia \\ e Great Lakes Institute for Environmental Research (GLIER), University of Windsor, Windsor, Ontario, Canada \\ ${ }^{\mathrm{f}}$ Department of Geology, University of Kansas, Lawrence, Kansas
}

\begin{abstract}
In the $>590$ - $\mathrm{m}$ deep, tropical Lake Matano (Indonesia), stratification is characterized by weak thermal gradients $\left(<2{ }^{\circ} \mathrm{C}\right.$ per $\left.500 \mathrm{~m}\right)$ and weak salinity gradients $(<0.14 \%$ per $500 \mathrm{~m})$. These gradients persist over seasons, decades, and possibly centuries. Under these nearly steady-state conditions, vertical eddy diffusion coefficients $\left(K_{z}\right)$ cannot be estimated by conventional methods that rely on time derivatives of temperature distributions. We use and compare several alternative methods: one-dimensional $k-\varepsilon$ modeling, three-dimensional hydrodynamic modeling, correlation with the size of Thorpe instabilities, and correlation with the stability frequency. In the thermocline region, at 100-m depth, the $K_{z}$ is $\sim 5 \times 10^{-6} \mathrm{~m}^{2} \mathrm{~s}^{-1}$, but, below $300 \mathrm{~m}$, the small density gradient results in large $(20 \mathrm{~m})$ vertical eddies and high mixing rates $\left(K_{z} \sim 10^{-2} \mathrm{~m}^{2} \mathrm{~s}^{-1}\right)$. The estimated timescale of water renewal in the monimolimnion is several hundred years. Intense evaporation depletes the surface mixed layer of ${ }^{16} \mathrm{O}$ and ${ }^{1} \mathrm{H}$ isotopes, making it isotopically heavier. The lake waters become progressively isotopically lighter with depth, and the isotopic composition in the deep waters is close to those of the ground and tributary waters. The vertical distribution of $K_{z}$ is used in a biogeochemical reaction-transport model. We show that, outside of a narrow thermocline region, the vertical distributions of dissolved oxygen, iron, methane, and phosphorus are shaped by vertical variations in transport rates, rather than by sources or sinks.
\end{abstract}

Few lakes are persistently stratified by temperature gradients alone (Crawford and Collier 2007; Boehrer et al. 2008). Persistent stratification is rare in lakes at temperate latitudes because seasonal variations in heat fluxes at the lake surface cause partial or complete turnover twice a year. Tropical lakes, with their weaker temperature gradients, are normally either completely mixed by the wind or stabilized by salinity gradients (Schmid et al. 2005; Boehrer and Schultze 2008). The possibility that weak temperature gradients alone can maintain meromixis (a situation that, perhaps, can be termed "thermogenic meromixis") is rarely considered; stable lakes without a salinity gradient are termed "oligomictic" and assumed to mix at irregular intervals (Hutchinson 1975). The best known aquatic environment where weak density gradients persist over large depth intervals is Lake Baikal, where the salinity below $250 \mathrm{~m}$ is low and constant, and the temperature $\left(\sim 3.5^{\circ} \mathrm{C}\right)$ is nearly invariant throughout the year (Ravens et al. 2000). Because such conditions are rare, mixing rates across weak but persistent density gradients in deep waters are poorly documented. Tropical lakes are

\footnotetext{
* Corresponding author: skatsev@d.umn.edu
}

${ }^{1}$ Present address: Nordic Center for Earth Evolution (NordCEE), Institute of Biology, University of Southern Denmark, Odense, Denmark particularly underrepresented in the literature, yet eddy diffusivities in these lakes can be notably different from those in temperate lakes (Lewis 1982).

The 590-m deep tropical Lake Matano (Fig. 1) is located in mountainous terrain on the Sulawesi Island of Indonesia. The highest point in the $436 \mathrm{~km}^{2}$ catchment basin is at $1700 \mathrm{~m}$ above sea level (a.s.1.), and the lake surface is located at $\sim 380 \mathrm{~m}$ a.s.l. The lake is tectonic in origin and sits in a steep-sided graben, which controls the bathymetry. Located at $2^{\circ} \mathrm{S}$ latitude, Lake Matano experiences minimal seasonal temperature fluctuations. The difference between the surface and bottom water temperatures is less than $3.5^{\circ} \mathrm{C}$ (Crowe et al. 2008a), a feature not uncommon in tropical lakes (Lewis 1982, 1987). Despite the weak temperature gradient, a persistent pycnocline situated at $\sim$ 100-m depth separates an oxic surface layer from anoxic bottom waters (Crowe et al. 2008a). Below 100-m depth, the salinity gradient is very weak (conductivity varies by less than $110 \mu \mathrm{S} \mathrm{cm}^{-1}$ over a 500-m depth interval) and the temperature gradient is less than $2^{\circ} \mathrm{C}$ per $500 \mathrm{~m}$. The gradients are virtually constant throughout the year and do not appear to differ from year to year (Crowe et al. 2008a).

Recent studies of Lake Matano have revealed an environment that is geochemically and microbiologically intriguing and possibly unique (Crowe 2008; Crowe et al. $2008 a, b)$. The anoxic waters below 100-m depth are virtually devoid of sulfide $\left(<0.6 \mu \mathrm{mol} \mathrm{L}^{-1}\right)$ but are rich 


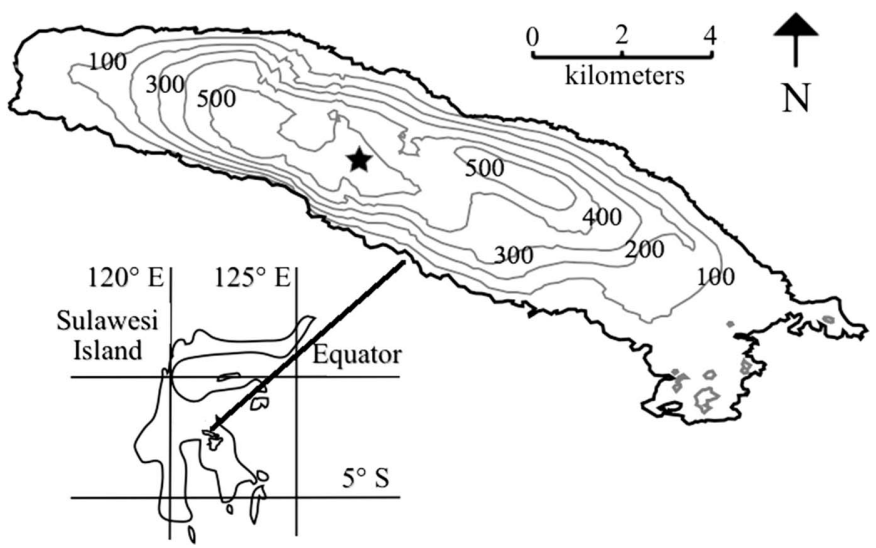

Fig. 1. Map showing the location of Lake Matano on Sulawesi Island, Indonesia, and bathymetric map of Lake Matano (isobaths are in meters). The star marks a central deep-water master station. The area below $\sim 100-\mathrm{m}$ depth is underlain by anoxic water.

in dissolved iron and methane (140 and $1400 \mu \mathrm{mol} \mathrm{L}-1$, respectively). Light penetration to $120-\mathrm{m}$ depth allows photosynthesis by a low-light adapted community of photoferrotrophic bacteria in the upper part of the anoxic water column, in a manner similar to what has been postulated for the Archean Ocean (Crowe et al. 2008b). The waters of Lake Matano may also support anaerobic oxidation of methane using ferric iron as an electron acceptor, a novel biogeochemical pathway (Crowe 2008; Beal et al. 2009; Crowe et al. in press). Since in situ rates of biogeochemical reactions depend on transport of reactants and products, quantifying physical mixing is essential for understanding the biogeochemical processes in this lake.

The constancy of the temperature gradient presents a methodological challenge to estimating transport coefficients. Most commonly used methods rely on recording the time derivatives of temperature profiles (Jassby and Powell 1975 ) and cannot be applied under the nearly steady-state conditions observed in Lake Matano. Crowe et al. (2008a) attempted to estimate the turbulent eddy diffusion coefficient, $K_{z}$, in the monimolimnion of Lake Matano by fitting the analytical solution of a simple reaction-transport model to an observed vertical distribution of dissolved $\mathrm{Fe}(\mathrm{II})$. Assuming a constant $K_{z}$ and iron reduction rates that decrease exponentially with depth below the persistent thermocline, they found that the value of $K_{z}(2.3 \times$ $10^{-2} \mathrm{~m}^{2} \mathrm{~s}^{-1}$ ) required to sustain the vertical fluxes of $\mathrm{Fe}$ was at least two orders of magnitude higher than in other lakes with persistent or permanent density gradients (Table 1). A similar problem was encountered in Lake Baikal, where $K_{z}$ values estimated from the vertical distributions of chlorofluorocarbons, oxygen, tritium, and helium (Killworth et al. 1996) differed by three orders of magnitude from values derived from the time derivatives of temperature profiles (Ravens et al. 2000).

This paper explores four alternative methods for determining $K_{z}$ : correlation with the sizes of overturning eddies, three-dimensional (3D) hydrodynamic modeling, $k-\varepsilon$ modeling, and correlation with the Brunt-Väisälä stability frequency. We compare the results from these methods and, using a stable isotope study of the lake water and major tributaries, elucidate the mixing regimes, mixing rates, and the long-term stability of the water column. Using a biogeochemical reaction-transport model, we show how the mixing regime in Lake Matano controls the vertical distributions of dissolved chemical substances.

\section{Methods}

Measurements of physical properties-Temperature profiles were recorded from September 2004 to February 2007 at the deepest site in Lake Matano by multiple casts of a conductivity-temperature-depth (CTD) probe. The 2002-2006 data were obtained with a Richard Brancker Research (RBR) CTD (accuracy $\pm 0.002^{\circ} \mathrm{C}$, precision $0.00005^{\circ} \mathrm{C}$ ), and these measurements cover both the dry (September) and the wet (February) seasons. Profiles recorded in February 2007 were acquired with a Seabird CTD (accuracy $0.005^{\circ} \mathrm{C}$, precision $0.0001^{\circ} \mathrm{C}$ ) from casts performed over a period of $5 \mathrm{~d}$, between 08:00 h and $12: 00 \mathrm{~h}$.

Stable isotope analyses-Water samples were collected in February 2007 (beginning of the wet season) from local fishing boats at a central, deep-water location $\left(2^{\circ} 28^{\prime} 00^{\prime \prime} \mathrm{S}\right.$, $\left.121^{\circ} 17^{\prime} 00^{\prime \prime} \mathrm{N}\right)$. Water samples were recovered from the water column using 5-liter Go-Flo (Niskin) bottles attached in series to a stainless steel cable and using a hand winch. The sampling depths were determined to an accuracy of \pm $1 \mathrm{~m}$ using a commercial fish finder (Furuno FCV-585). Water samples were transferred directly from the Niskin bottle's spigot into $15-\mathrm{mL}$ screw-cap tubes filled to overflow so there would be little or no headspace. In addition, water samples from two of the lake's main tributaries (La Wa, La Molengku), a groundwater collection pool (Spring Kampung Matano), and a single rain event were collected by hand.

The stable isotopic composition $\left(\delta^{2} \mathrm{H}\right.$ and $\left.\delta^{18} \mathrm{O}\right)$ of the water samples was analyzed at the GEOTOP laboratories. For $\delta^{2} \mathrm{H}$ measurements, water samples and two laboratory internal reference waters were transferred to $1.5-\mathrm{mL}$ vials with no headspace and closed with a septum cap. The vials were mounted on a Micromass PyroH automatic sampling system from which $0.3 \mu \mathrm{L}$ of water was withdrawn by a microsyringe and injected onto hot chromium $\left(1050^{\circ} \mathrm{C}\right)$ under a helium flow. The resulting gases were separated using a gas chromatography column and analyzed on a Micromass Isoprime double collector isotope ratio mass spectrometer in continuous flow mode. A correction was made for the production of tritium in the gas source of the mass spectrometer. Data were normalized against the two internal reference waters, both calibrated against the Vienna standard mean ocean water (V-SMOW) and Vienna standard light Antarctic precipitation (V-SLAP). Data are expressed in \%o with respect to V-SMOW, and replicate measurements of sample waters are better than $1 \%$. For $\delta^{18} \mathrm{O}, 200-\mu \mathrm{L}$ aliquots of the water samples and two laboratory internal reference waters were transferred into $3-\mathrm{mL}$ vials stoppered with a septum cap. The vials were then 


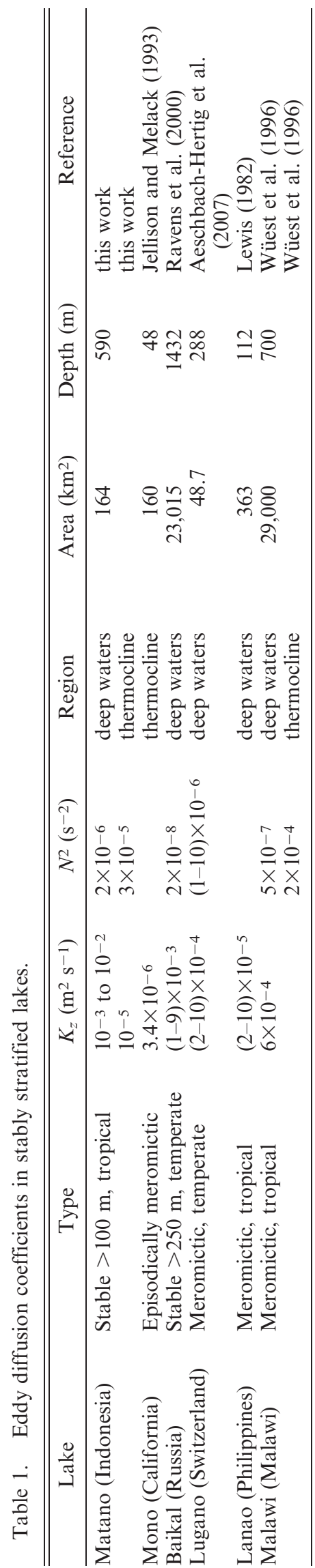

placed in a heated rack maintained at $40^{\circ} \mathrm{C}$. Commercially available $\mathrm{CO}_{2}$ gas was introduced in all the vials using a Micromass AquaPrep and allowed to equilibrate for $7 \mathrm{~h}$. The headspace $\mathrm{CO}_{2}$ was then sampled by the Micromass AquaPrep, dried on a $-80^{\circ} \mathrm{C}$ water trap, and analyzed on a Micromass Isoprime universal triple collector isotope ratio mass spectrometer in dual inlet mode. Data were normalized against the two internal reference waters, both calibrated against V-SMOW and V-SLAP. Data are expressed in \%o with respect to V-SMOW, and replicate measurements of sample waters are better than $0.05 \%$.

3D hydrodynamic modeling - Three-dimensional hydrodynamic modeling of Lake Matano was performed using the estuary lake and coastal ocean model (ELCOM; Hodges and Dallimore 2007). The bathymetry of Lake Matano (Fig. 1) was discretized on a rectangular $23 \times 55$ grid with a cell size of $340 \times 500 \mathrm{~m}$. The vertical grid step was $3 \mathrm{~m}$ in the depth interval between 0 and $159 \mathrm{~m}$, and increased linearly below it, reaching $41 \mathrm{~m}$ in the lowermost layer, to a total of 72 grid layers. Water temperature and salinity were specified as initial conditions according to their respective measured vertical distributions, with no lateral variations. Meteorological data were generated at a half-hour time resolution to match the monthly averages and other typical values of the respective parameters, as shown in Fig. 2. Time-independent model parameters are specified in Table 2. ELCOM's control switches were adjusted to include program modules that calculate surface thermodynamics, inflows and outflows, stratification by temperature and salinity, baroclinic forcing, rainfall input, and the Coriolis force.

One-dimensional (1D) hydrodynamic modeling-Onedimensional hydrodynamic modeling of Lake Matano was performed using the lake compartment of the AQUASIM modeling environment (Reichert 1998). The vertical grid consisted of 200 equally spaced depth levels. The user-specified parameters (Table 3) and expressions were as follows. The rate of heating $\left(\mathrm{K} \mathrm{s}^{-1}\right)$ by solar radiation was taken as $[H /(\rho c)] \lambda \exp (-\lambda z)$, where $H$ is the density $\left(\mathrm{W} \mathrm{m}^{-2}\right)$ of solar radiation at the lake surface; $\rho$ and $c$ are, respectively, the density and heat capacity of water; $\lambda$ is the coefficient of light attenuation; and $z$ is depth. Evaporative cooling rate $\left(\mathrm{K} \mathrm{s}^{-1}\right)$ was, for numerical convenience, assumed to be confined to the upper $10 \mathrm{~m}$ of water and was calculated as $\left[E_{\mathrm{av}} /(\rho c)\right] 10 \exp (-10 z)$. The average evaporative heat flux $E_{\mathrm{av}}\left(\mathrm{W} \mathrm{m}^{-2}\right)$ was specified explicitly (Table 3$)$. Cooling rate $\left(\mathrm{K} \mathrm{s}^{-1}\right)$ due to the heat loss to sediments was described by $\left[Q_{\text {sed }} /(\rho c)\right] \alpha_{\text {sed }}(T-$ $\left.T_{\text {sed }}\right)(-d A / d z)\left(1 / A_{0}\right)$, where $T_{\text {sed }}$ is the temperature of the sediments, $A_{0}$ is the surface area of the lake, and the term $d A / d z$ accounts for the decrease in the sediment area with depth. The value of the coefficient $\alpha_{\text {sed }}\left(\mathrm{K}^{-1}\right)$ was chosen such that the total heat loss to sediments integrated over the depth of the lake equaled $Q_{\text {sed }}\left(\mathrm{W} \mathrm{m}^{-2}\right)$ (Table 3$)$. An influx of $21^{\circ} \mathrm{C}$ groundwater was considered in the depth range $250-300 \mathrm{~m}$ at a rate of $1.3 \mathrm{~m}^{3} \mathrm{~s}^{-1}$ (see section on heat fluxes and groundwater inflows below for justification). This small rate did not to affect the stratification structure 

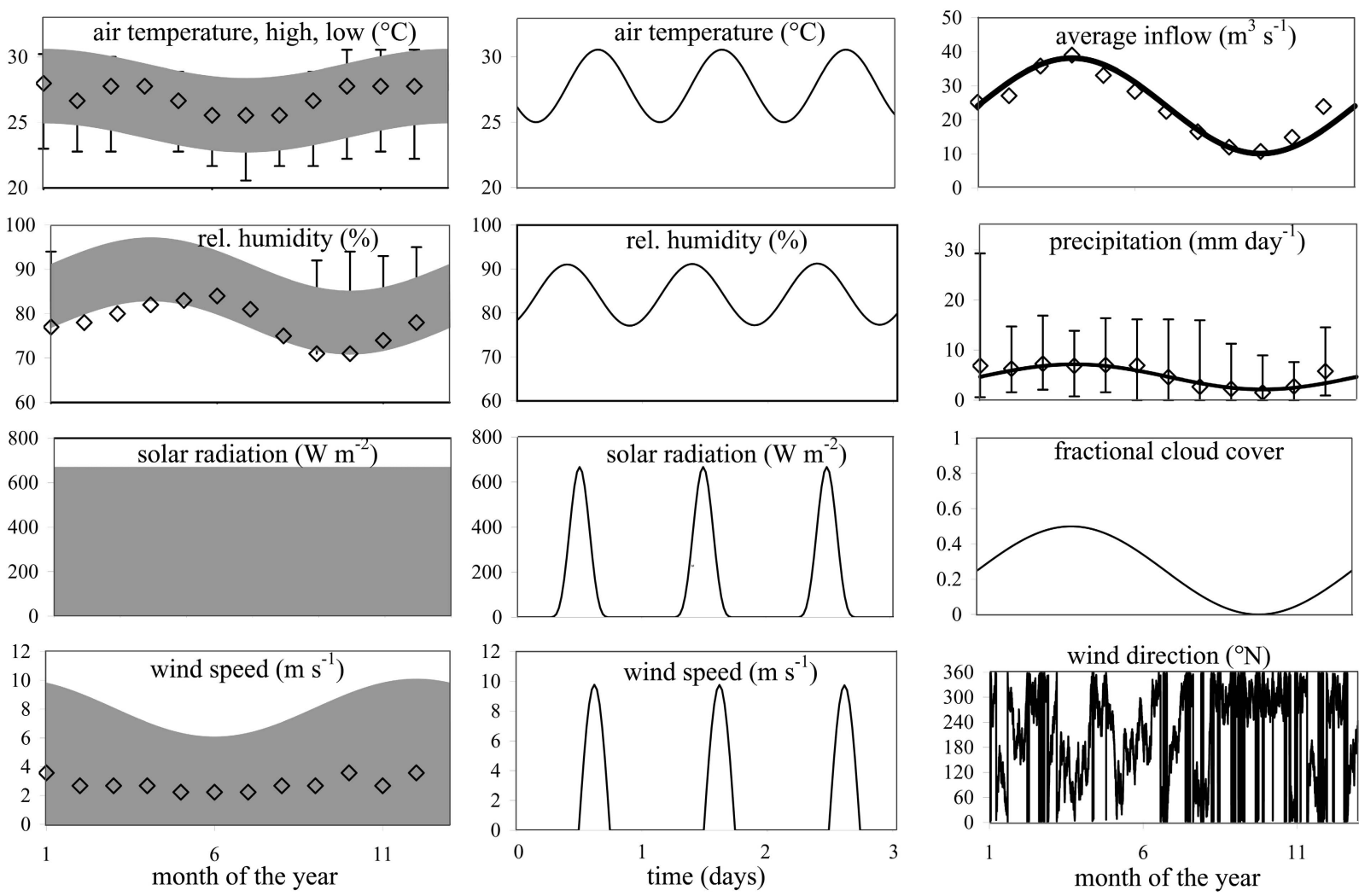

Fig. 2. Temporal inputs for the 3D and 1D hydrodynamic models. Data points and error bars indicate, respectively, the monthly averages and typical variabilities for the corresponding meteorological parameters in the Matano region. The first column shows annual variation. Gray bands indicate the ranges of daily variations, which are shown at a higher temporal resolution in the second column. Data points for humidity represent typical daily minima and error bars extend to daily maxima. Data are from http://www.weatherreports. com/Indonesia/Soroako/averages.html and courtesy of INCO, Tbk.

of the water column on the timescales of the simulation. Since the numerical heat diffusion in the model prevented the simulations from reaching steady state, a steady-state heat balance was approximated by the enforced equality of the time-averaged heat fluxes in and out of the water column: $H_{\mathrm{av}}=E_{\mathrm{av}}+Q_{\text {sed }}$.

The model was initialized with the measured temperature and salinity distributions (Fig. 3) and was run for a period of several months. Meteorological inputs included solar insolation, wind speed, and cloud cover, which followed the temporal behaviors shown in Fig. 2. AQUASIM's control

Table 2. ELCOM 3D hydrodynamic model: time-independent user-specified parameters. PAR, photosynthetically active radiation; NIR, near infrared radiation; UVA, ultraviolet A (long wave) radiation; UVB, ultraviolet $\mathrm{B}$ (medium wave) radiation.

\begin{tabular}{llll}
\hline \hline \multicolumn{1}{c}{ Parameter } & Value & Units & Reference \\
\hline Light extinction coefficients & & & \\
PAR & 0.0465 & $\mathrm{~m}^{-1}$ & Crowe et al. (2008b) \\
NIR & 0.186 & $\mathrm{~m}^{-1}$ & \\
UVA & 0.186 & $\mathrm{~m}^{-1}$ & \\
UVB & 0.465 & $\mathrm{~m}^{-1}$ & \\
Mean albedo & 0.08 & - & \\
Bottom drag coefficient & 0.005 & - & \\
\hline
\end{tabular}

switches were adjusted to include calculations of turbulent kinetic energy in the water column. Following the suggestions in the AQUASIM user manual, the magnitude of the surface shear $\left(\mathrm{N} \mathrm{m}^{-2}\right)$ generated by wind at the lake surface was simulated according to a standard $k-\varepsilon$ model

Table 3. AQUASIM 1D hydrodynamic model: timeindependent user-specified parameters.

\begin{tabular}{lccl}
\hline \hline Parameter & Value & Units & Reference \\
\hline$H_{\text {av }}$ & 250 & $\mathrm{~W} \mathrm{~m}^{-2}$ & \\
$E_{\text {av }}$ & 249.8 & $\mathrm{~W} \mathrm{~m}^{-2}$ & \\
$Q_{\text {sed }}$ & 0.2 & $\mathrm{~W} \mathrm{~m}^{-2}$ & \\
$T_{\text {sed }}$ & 25.57 & ${ }^{\circ} \mathrm{C}$ & \\
$\lambda$ & 0.186 & $\mathrm{~m}^{-1}$ & Crowe et al. 2008b \\
Bottom drag & & & \\
$\quad$ coefficient & 0.005 & - & \\
$A_{0}$ & 164 & $\mathrm{~km}^{2}$ & \\
$V$ & 38 & $\mathrm{~km}^{3}$ & \\
$c_{10}$ & 0.001 & - & Reichert (1998) \\
$\tau_{\text {seiche }}$ & 3 & $\mathrm{~d}$ & \\
$\alpha$ & $10^{-4}$ & - & Reichert (1998) \\
$\rho_{\text {air }}$ & 1.2 & $\mathrm{~kg} \mathrm{~m}^{-3}$ & \\
$c_{1}$ & 1.44 & - & Reichert (1998) \\
$c_{2}$ & 1.92 & - & Reichert (1998) \\
$c_{3}$ & 0 & - & Reichert (1998) \\
$c_{\mu}$ & 0.09 & - & Reichert (1998) \\
\hline
\end{tabular}




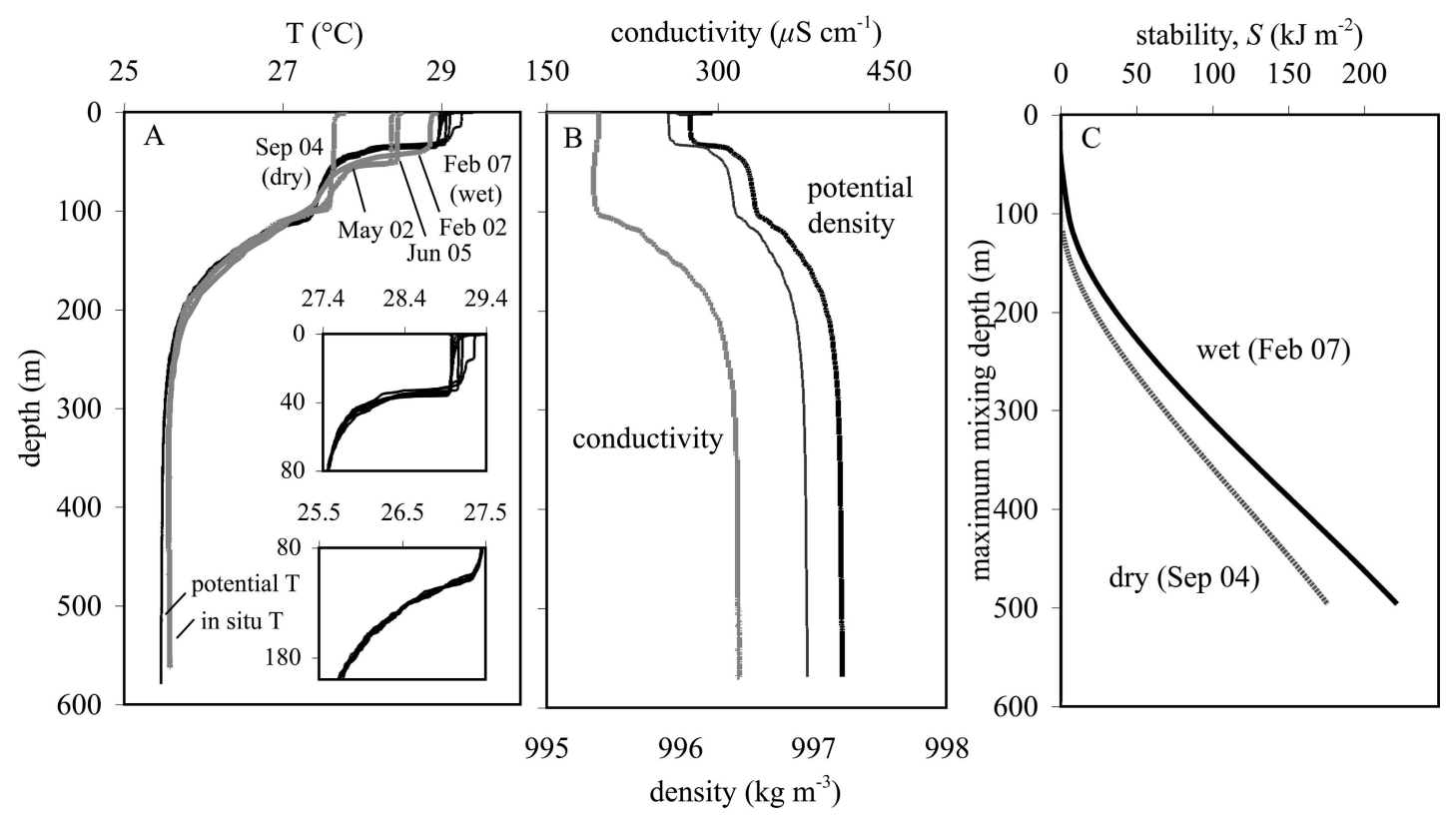

Fig. 3. (A) Temperature profiles recorded at the deepest location in Lake Matano. The potential temperature profiles recorded in February 2007 (black) cover a time span of $9 \mathrm{~d}$ and were recorded between 08:30 h and 12:30 h. Potential temperature, rather than in situ temperature, is reported since it accounts for the effect of the compressibility of water on the water column stability (Peeters et al. 1996). The difference between the potential temperature (black) and the in situ temperature (gray) below $250 \mathrm{~m}$ illustrates the effect. Insets show the February 2007 profiles in more detail in the epilimnion and immediately below the persistent thermocline. (B) In situ conductivity (February 2007, gray) and the potential density of water, as calculated from temperature alone (thin black) and the combined temperature and conductivity (thick black). (C) Stability $S$ (see Eq. 3), i.e., the energy per unit area that needs to be supplied to eliminate the density gradient in a depth range between the surface and depth $z_{m}$.

(Amorocho and de Vries 1980) as $\rho_{\text {air }} c_{10}\left(w_{10}\right)^{2}$, where $c_{10}$ is the drag coefficient and $w_{10}$ is the wind speed at $10-\mathrm{m}$ altitude. The power (W) transferred into the seiche motion by wind was described by $\alpha A_{0} \rho_{\text {air }} c_{10}\left|w_{10}\right|^{3}$, with the coefficient $\alpha$ given in Table 3. The power (W $\mathrm{kg}^{-1}$ ) dissipated by seiches per unit mass of water due to internal friction was described by $E_{\text {seiche }} /\left(V \rho \tau_{\text {seiche }}\right)$, where $\tau_{\text {seiche }}(\mathrm{s})$ is the decay rate constant and $V$ is the lake volume. The seiche energy, $E_{\text {seiche }}$, is an internal AQUASIM parameter and was calculated by the program at each iteration step at all depth levels. For dissipation $\varepsilon\left(\mathrm{W} \mathrm{kg}^{-1}\right)$ of turbulent kinetic energy (TKE), the rate of $\varepsilon$ production $\left(\mathrm{W} \mathrm{kg}^{-1} \mathrm{~s}^{-1}\right)$ within the water column was described by a standard $k-\varepsilon$ model expression (Amorocho and de Vries 1980): $c_{1}(P+$ $\left.c_{3} G\right)(\varepsilon / k)-c_{2}\left(\varepsilon^{2} / k\right)$. Here, $k\left(\mathrm{~J} \mathrm{~kg}^{-1}\right)$ is the turbulent kinetic energy (TKE) per unit mass of water, $P\left(\mathrm{~W} \mathrm{~kg}^{-1}\right)$ is the production of TKE due to shear of horizontal velocity, and $G\left(\mathrm{~W} \mathrm{~kg}^{-1}\right)$ is the production or loss of TKE due to density differences. $P, G$, and $\varepsilon$ were calculated by the program internally (Reichert 1998). Parameters $c_{1}, c_{2}$, and $c_{3}$ were assigned their standard values (Table 3). The coefficient of vertical turbulent diffusion, $K_{z}\left(\mathrm{~m}^{2} \mathrm{~s}^{-1}\right)$ was calculated using a turbulence submodel with parameterization (Reichert 1998) $K_{z}=c_{\mu} k^{2} /(\varepsilon \operatorname{Pr})$, where $\operatorname{Pr}$ is the Prandtl number and $c_{\mu}$ is given in Table 3 .

Results

Density stratification - The temperature profiles in Lake Matano show a persistent thermocline near 100-m depth and a seasonal thermocline higher in the water column (Fig. 3A). In February 2007, the seasonal thermocline was located at a depth of $35 \mathrm{~m}$. The temperature below the persistent thermocline remained virtually constant throughout the entire measurement period. Small temporal temperature fluctuations, believed to result from internal waves, were observed in the depth interval between the persistent thermocline and 300-m depth. The internal wave vertical amplitudes at the depth of the thermocline were on the order of $4 \mathrm{~m}$. Below $350 \mathrm{~m}$, the temperature profiles are identical over depth and time within the accuracy of the instruments.

The salinity contribution to the water column stability is illustrated in Fig. 3B. In marine systems, salinity is commonly computed from the electrical conductivity of water. In fresh waters, where the ionic composition is more variable, the relationship between conductivity and the total dissolved solids content can be different, and the water density may depend on the concentrations of nonionic species. For example, in Lake Malawi, the water column stability is influenced by the vertical distribution of dissolved silica (Wüest et al. 1996). In Lake Matano, dissolved $\mathrm{Si}$ (with maximum concentration of $11 \mathrm{mg} \mathrm{L}^{-1}$ or $390 \mu \mathrm{mol} \mathrm{L}^{-1}$; Crowe 2008) is not an important factor. Water density in Fig. 3B was calculated from temperature and salinity using the expression of Chen and Millero (1986), the CTD measurements of temperature and conductivity, and a conductivity-to-salinity conversion factor of $0.0010\left(\mathrm{~g} \mathrm{~kg}^{-1}\right) /\left(\mu \mathrm{S} \mathrm{cm}^{-1}\right)$ that was established from the measured vertical distributions of ionic and 

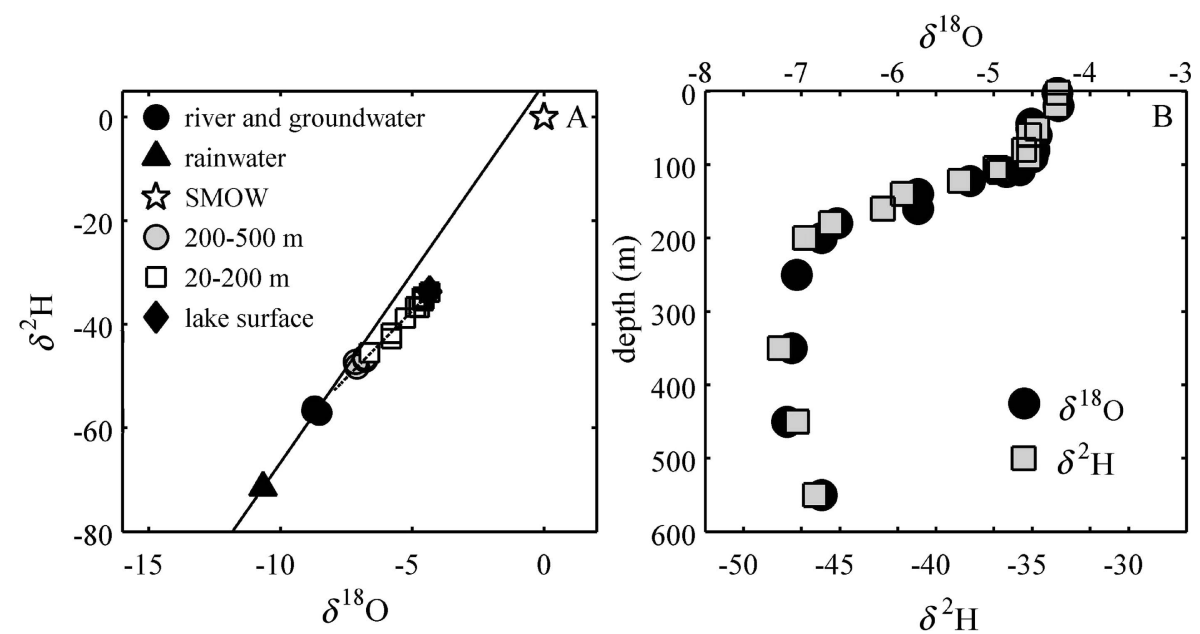

Fig. 4. (A) The isotopic composition of Lake Matano waters, tributary waters, and rain waters. Local meteoric water line (solid line) is $y=7.31 x+6.44$. The regression fit to the Matano data (secondary evaporative line; dashed line) is $y=5.18 x-11.47\left(r^{2}=0.99\right)$. (B) Depth distributions of oxygen and deuterium isotopes in Lake Matano.

nonionic species in the water column of Lake Matano, as given in Crowe (2008) (the maximum concentration of $\mathrm{Ca}$ is $558 \mu \mathrm{mol} \mathrm{L}^{-1} ; \mathrm{Mg}, 831 \mu \mathrm{mol} \mathrm{L}^{-1} ; \mathrm{Fe}, 139 \mu \mathrm{mol} \mathrm{L}^{-1}$; Na, $76 \mu \mathrm{mol} \mathrm{L}^{-1} ; \mathrm{K}, 7.2 \mu \mathrm{mol} \mathrm{L}^{-1} ; \mathrm{NH}_{4}^{+}, 177 \mu \mathrm{mol} \mathrm{L}^{-1}$; and $\left.\mathrm{HCO}_{3}^{-}, 2930 \mu \mathrm{mol} \mathrm{L}-1\right)$. The water density calculated from the CTD data mimics the density curve that was calculated directly from the measured concentrations of dissolved solids following the method of Wüest et al. (1996).

Isotopic composition of water-The isotopic compositions of the local rain, tributary, and groundwaters (Fig. 4) define a local meteoric water line (with a slope of 7.3), which is nearly coincident with the one reported by Varekamp and Kreulen (2000) for eastern Indonesia and shifted to more negative $\delta^{18} \mathrm{O}$ for equivalent $\delta^{2} \mathrm{H}$ with respect to the global meteoric water line (Craig 1961; Rozanski et al. 1993). The enrichment of $\delta^{2} \mathrm{H}$, relative to $\delta^{18} \mathrm{O}$, in precipitation is typical of monsoonal rains in Southeast Asia (Araguás-Araguás et al. 1998) and reflects the source of atmospheric moisture during the rainy season. The isotopic composition of the lake waters defines an evaporative trend (Gat 1996) to the right of the local meteoric water line: the surface waters provide the evaporative end-member and bottom waters trend toward the local meteoric water line and the composition of tributary and groundwaters. The lake waters are isotopically heaviest in the epilimnion, become progressively lighter across the metalimnion (100-200 m), and remain relatively invariant in the monimolimnion. The water below $500 \mathrm{~m}$ is slightly heavier than the water above this depth (Fig. 4).

Eddy diffusion rates - Turbulent eddy diffusion is commonly the predominant mixing mechanism in the deep waters of stratified lakes. In the absence of evidence for large-scale convection, and because Lake Matano receives the inputs from only three small tributaries, this is likely true for Lake Matano as well, although we propose additional mixing mechanisms later in this paper. Commonly used methods for calculating the eddy diffusion coefficient, $K_{z}$, use temporal changes in the water temperature that arise from seasonal or diurnal variations in vertical heat fluxes and rely on a time derivative of the temperature profile (Jassby and Powell 1975). In Lake Matano, however, such time derivatives in the depth interval around and below the thermocline are null for timescales longer than several hours, which renders these methods unusable. Data with higher temporal resolution are unavailable, but their relevance for our purposes would be questionable, since they would be influenced by the instantaneous wind conditions and would not represent any long-term averages. Below, we explore four alternative methods for determining $K_{z}$ and compare their results and relative merits.

Correlation with sizes of overturning eddies-The vertical eddy diffusivity coefficient, $K_{z}$, is linked to the vertical size of overturning eddies through an empirical relationship (Imboden and Wüest 1995):

$$
K_{z}=\gamma_{\text {mix }} L_{\mathrm{T}}^{2} N
$$

where $\gamma_{\text {mix }}$ is the fraction of the wind-derived turbulent kinetic energy that is transferred into the buoyancy flux, $N$ is the Brunt-Väisälä frequency that characterizes the density gradient, and $L_{\mathrm{T}}$ is the root-mean-square vertical size of the so-called Thorpe displacements (Thorpe and Hall 1977). The latter are eddy instabilities in the water column that cause denser water to temporarily overlie less dense water, as measured along the same vertical profile. Far from the energetic surface layers, the Thorpe scale $L_{\mathrm{T}}$ is a good approximation for the length scale within which the stratification permits buoyancy instabilities (the Ozmidov scale, $L_{\mathrm{O}}$ ) (Dillon 1982). We determined $L_{\mathrm{T}}$ from a vertical density profile that was calculated from the temperature and conductivity data recorded in February 2007 by a 


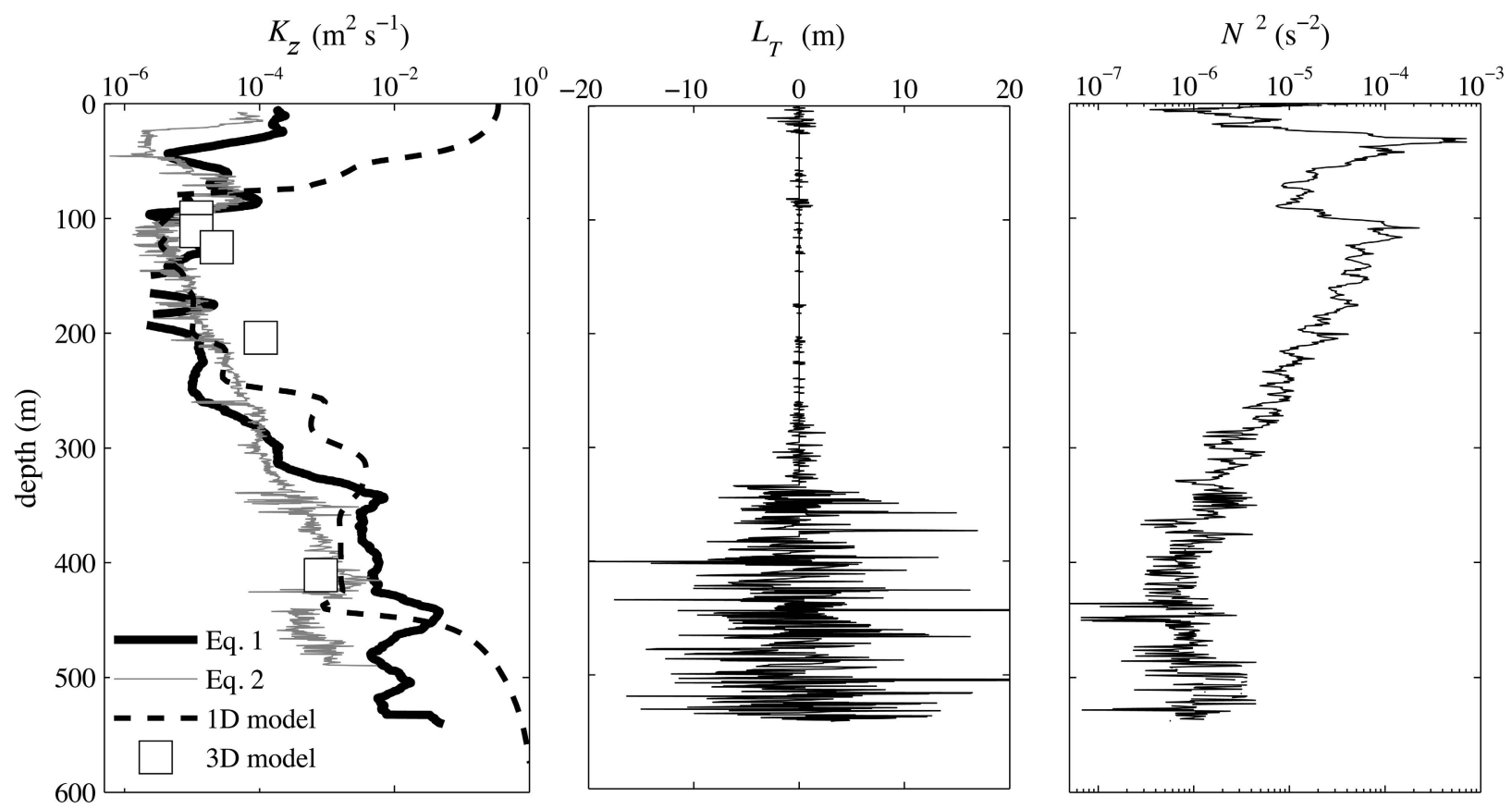

Fig. 5. (A) Vertical eddy diffusivity, $K_{z}$, estimated from several methods: the Thorpe length scale of overturning eddies (Eq. 1); dissipation of a nonreactive tracer in a $3 \mathrm{D}$ hydrodynamic model; one-dimensional $k-\varepsilon$ model; and empirical correlation with the BruntVäisälä stability frequency (Eq. 2). (B) The vertical size of the overturning eddies (Thorpe displacements), $L_{\mathrm{T}}$, as determined from a density profile recorded in February 2007. (C) Square of the Brunt-Väisälä stability frequency, $N^{2}$.

freefalling CTD. A value of 0.12 , typical for shear-induced mixing in lake hypolimnia, was assigned to $\gamma_{\text {mix }}$ (Imboden and Wüest 1995).

The calculated vertical size of the overturning eddies is shown in Fig. 5B, and the computed $K_{z}$ values are presented in Fig. 5A. The eddy diffusivity coefficient is smallest at the persistent (100-m depth) thermocline, where its value $\left(\sim 5 \times 10^{-6} \mathrm{~m}^{2} \mathrm{~s}^{-1}\right)$ is similar to our previous estimate (Crowe et al. 2008a). The eddy diffusivities above the seasonal thermocline reach approximately $1.7 \times$ $10^{-4} \mathrm{~m}^{2} \mathrm{~s}^{-1}$. Below $350 \mathrm{~m}$, where the potential temperature and conductivity gradients (Crowe et al. 2008a) are small

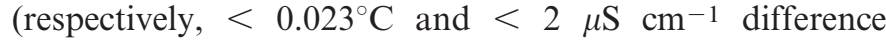
between $350-$ and $550-\mathrm{m}$ depth), there is little impediment to vertical mixing in the water column. This results in extremely large eddies, 2 to $20 \mathrm{~m}$ in size (Fig. 5B). Such large eddies must also exist in other deep aquatic systems, such as Lake Baikal, where similarly large values of $K_{z}$ were estimated (Ravens et al. 2000). The weak density gradient below $350 \mathrm{~m}$ results in a paradoxical situation where $K_{z}$ in the deep and intuitively quiet waters is two orders of magnitude greater (up to $10^{-2} \mathrm{~m}^{2} \mathrm{~s}^{-1}$ ) than in the epilimnion. This conclusion, also observed in some other studies (Rohden and Ilmberger 2001), is supported by the geochemical data presented below.

$3 D$ hydrodynamic modeling - One-dimensional data obtained at a middle-of-the-lake location (Crowe et al. 2008a) may not always provide accurate representations of the lake averages. To account for the three-dimensional aspects of physical mixing, we simulated the mixing dynamics of Lake Matano using the hydrodynamic ELCOM (Hodges and Dallimore 2007). The model accounts for the effects of lake bathymetry, inflows and outflows of water, and other environmental parameters including wind, evaporation, and penetration of solar radiation. To accurately reproduce observations, such as temperature evolutions, models of this kind typically require extensive meteorological datasets. These data were unavailable for Lake Matano. Nevertheless, because the lake can be approximated as being at steady state, and because we are only interested in long-term, time-averaged characteristics, it is sufficient that model inputs reproduce only typical, rather than specific, variations in the lake environment. We therefore provided the model with artificially generated atmospheric data with a mean and variance that corresponded to typical values observed at Lake Matano (Fig. 2). When run over a period of $1 \mathrm{yr}$ from an initial condition given by the measured temperature and salinity distributions, the model reproduced the epilimnion warming during the wet season and cooling by evaporation during the dry season. Consistent with observations, simulations indicate that the temperature in the epilimnion above the seasonal thermocline varies also on a diurnal timescale (resulting in a third, diurnal, thermocline at a depth of around $20 \mathrm{~m}$ ) and that wind disturbances propagate deep into the monimolimnion (Fig. 6A).

The vertical eddy diffusivity coefficient, $K_{z}$, was estimated from the simulated dispersion of a nonreactive tracer. To exclude the three-dimensional effects and resolve only the vertical diffusion, the tracer was continuously introduced in the model in an entire horizontal grid layer at a depth where $K_{z}$ was to be determined (Fig. 6C). In the absence of boundaries, the tracer dispersion in the vertical 


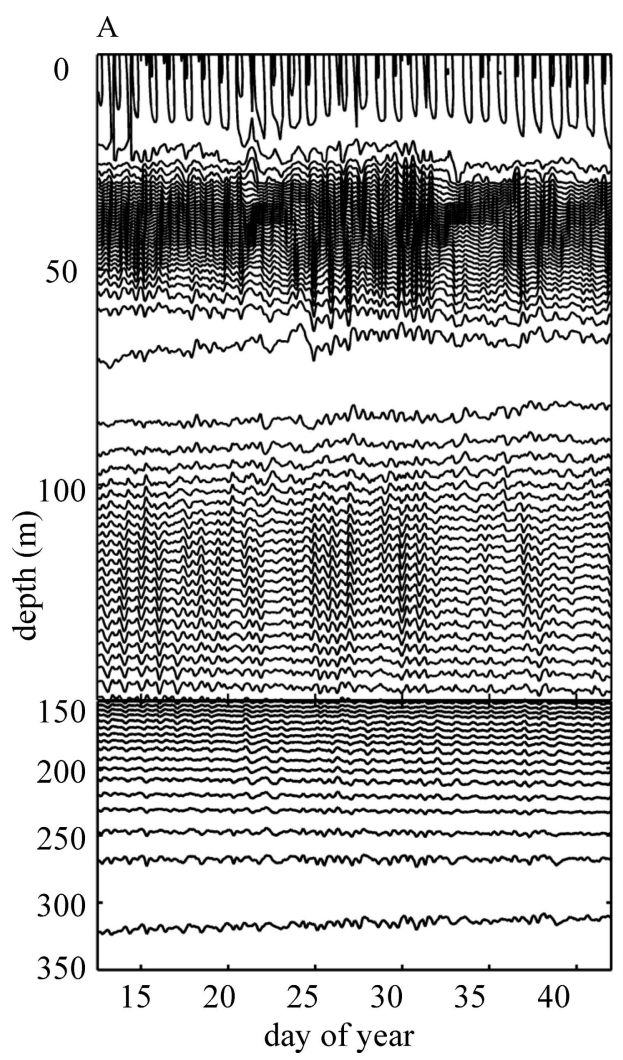

B

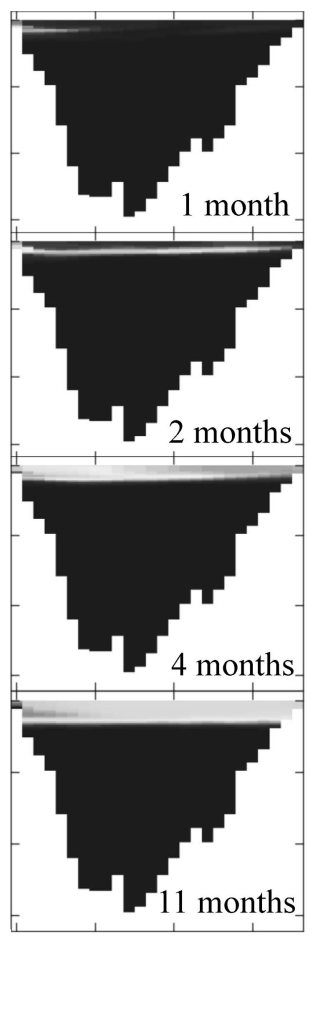

$\mathrm{C}$

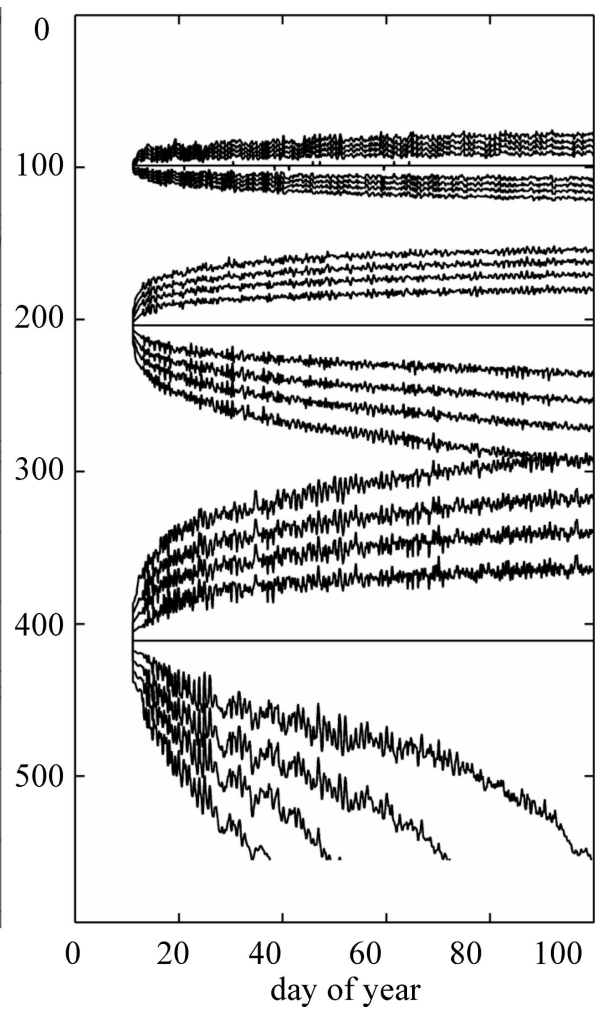

Fig. 6. Results from 3D hydrodynamic modeling. (A) Typical variations in lake temperature in the depth range 0-350 $\mathrm{m}$ over a period of about 1 month. Lines are the isotherms at $0.05^{\circ} \mathrm{C}$. The depth interval below $150 \mathrm{~m}$ is shown at a different vertical scale, for clarity. Since the simulations were initiated with no internal waves in the water column, the initial transient is omitted from the figure. (B) Continuous release of a tracer at the mouth of an inflowing river. Shown are the concentrations (in arbitrary units) along the longest transect, which extends roughly in the northwest-to-southeast direction. (C) Dispersion of tracers after their release on day 11 at different depths. The concentrations at the release depths are constant in time; contour intervals are 0.2 of the maximum.

direction is equivalent to free diffusion from an inexhaustible reservoir, a problem for which an analytical solution is available (Katsev and L'Heureux 2002):

$$
C=C_{0} \operatorname{erfc}\left[\frac{h}{2 \sqrt{K_{z} t}}\right]
$$

Here, $C_{0}=$ const and $C$ are, respectively, the tracer concentrations at the release depth and at the distance $h$ above or below it. The diffusion coefficient, $K_{z}$, was obtained by fitting the vertical distributions, $C(t, h)$, at subsequent moments of time. To minimize errors associated with the fact that $K_{z}$ varies with depth, calculations were restricted to five adjacent grid layers. The derived diffusion coefficients are shown in Fig. 5A. Slightly higher values of $K_{z}$ were obtained in the thermocline region compared with the results from other methods. This could be partly an artifact due to seiching, which displaces the water vertically relative to the fixed grid and causes the tracer to be effectively released in more than one grid layer, and partly the result of the finite grid size, which effectively shortens the distance between the depth of tracer release and the depth at which it is monitored. The former problem can be eliminated by introducing the tracers at a single moment of time, instead of continuously, in which case the tracer depth distributions become approximately Gaussian. Fitting of such distributions produces similar values of $K_{z}$, but the approach does not improve accuracy. The discreteness of the grid, combined with the temporal fluctuations in mixing rates, still generates a relatively large dispersion in the values of $K_{z}$.

One-dimensional $k-\varepsilon$ modeling - A class of hydrodynamic models, termed $k-\varepsilon$ models, yields the mixing intensities of water bodies in one dimension, in effect performing lateral averaging. While losing some information with respect to three-dimensional models, these one-dimensional models gain in computation speed. We used the $k-\varepsilon$ model in the AQUASIM modeling environment (Reichert 1994). The simulated eddy diffusivity coefficients $K_{z}$ are shown in Fig. 5A. The $K_{z}$ values in the vicinity of the thermocline agree with the values (in Fig. 5A) obtained by other methods. The model also returns higher values of $K_{z}$ in the lower epilimnion and in the deep waters, but mixing in the upper epilimnion is overestimated compared to the other methods.

$K_{z}$ vs. $N^{2}$ correlation-The mixing intensity, as characterized by $K_{z}$, is the result of a balance between the stratification stability of the water column and the intensity 


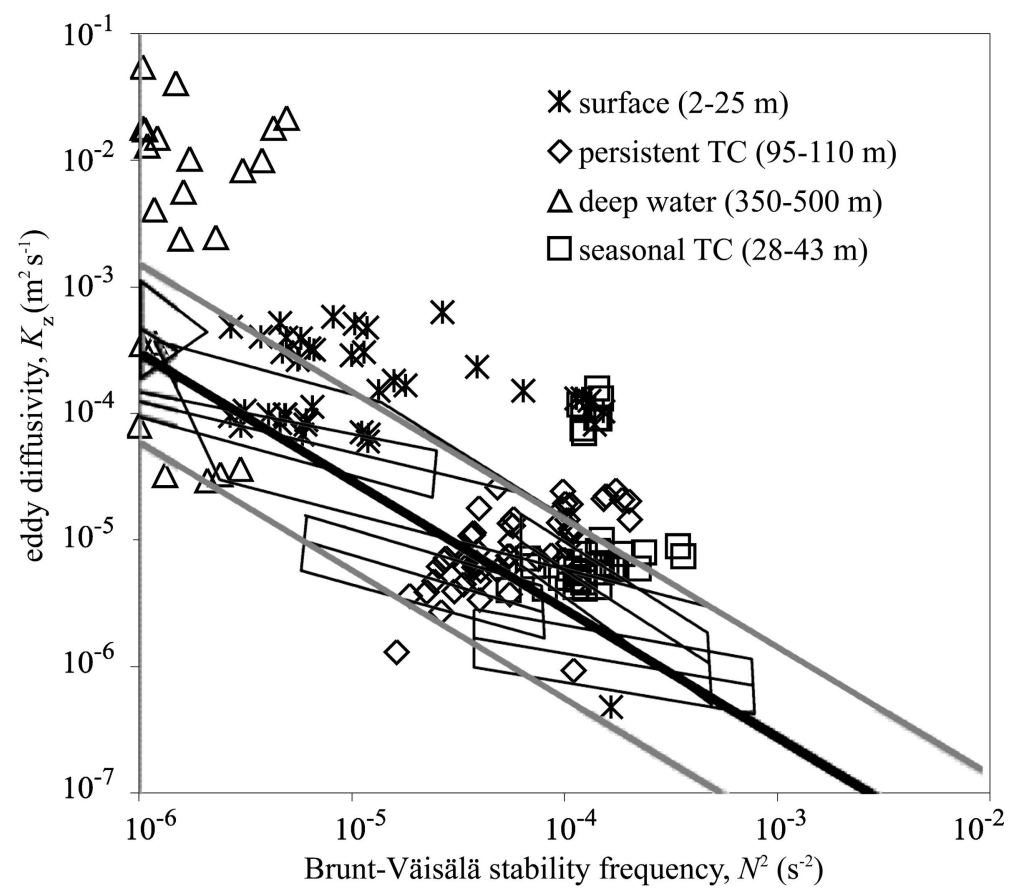

Fig. 7. $K_{z}$ vs. $N^{2}$ relationship from literature (outlines, modified from Lerman 1979) and in Lake Matano at various depths (symbols). The thick black line corresponds to Eq. 2. TC $=$ thermocline.

of the driving forces of mixing. The stratification stability is commonly represented by the square of the Brunt-Väisälä frequency, $N^{2}$, which can be calculated from a measured density gradient (Lorke and Wüest 2005). The forcing part of the balance is strongly dependent on the lake environment and is generally independent of $N^{2}$. Nevertheless, empirical relationships have been proposed that indicate an inverse power-law relationship between $K_{z}$ and $N^{2}$. Figure 7 shows a compilation of literature values for the vertical eddy diffusivity and stability frequency in a variety of natural waters, from shallow lakes to the deep ocean (Hutchinson 1975; Lerman 1979; Quay et al. 1980). The relationship between $K_{z}$ and $N^{2}$ is relatively well described (within a factor of 5) by a power-law relationship:

$$
K_{z}=a\left(N^{2}\right)^{-b}
$$

where $a=3 \times 10^{-10}, b=1, K_{z}$ is in $\mathrm{m}^{2} \mathrm{~s}^{-1}$, and $N$ is in $\mathrm{s}^{-1}$ (Fig. 7). The data for Lake Matano generally agree with this pattern (Fig. 7). Figure 5A shows the $K_{z}$ profile that was obtained from Eq. 2, where $N^{2}$ was calculated from the measured temperature and salinity profiles. The agreement with other methods is fairly good, both in the epilimnion and in the deep waters. The value of the scaling constant $(b=1)$ may reflect the dominant mixing mechanism: Welander (1968) suggested that $b=1$ is indicative of turbulence being generated by large-scale horizontal eddies that cascade down into smaller eddies, whereas turbulence by local shear should result in $b=0.5$ (Jellison and Melack 1993).

Seiching - The temperature profiles (Fig. 3A, insets), as well as hydrodynamic simulations (Fig. 6A), indicate that, at a middle-of-the-lake location, wind-induced seiching causes vertical movements of water masses with amplitudes on the order of $4-10 \mathrm{~m}$ and a typical period of several hours. Internal waves in Lake Matano, which are expected to be predominantly damped linear waves (Horn et al. 2001), persist well into the monimolimnion, down to $350 \mathrm{~m}$ (Figs. 3A, 6A). The timescale of several hours is consistent with the theoretical order-of-magnitude estimate: the expression of Imboden and Wüest (1995) for the lowest mode of baroclinic seiches resulting from "horizontal mode" oscillations yields a period of 4-10 h.

\section{Discussion}

Long-term stability and deep-water renewal-Lakes that have moderate surface area and great depth and are located in regions of high humidity can exhibit stratification that appears stable over years, but their waters can, nevertheless, mix at irregular intervals, e.g., after a rare cold or dry spell (Hutchinson 1975). Short of complete overturn, an intermediate situation can develop when unusually cold or dry weather or strong persistent winds causes local mixing and partial mixing of the epilimnetic and deep waters. Deep waters of stably stratified lakes may also be renewed gradually, as a result of a large-scale water circulation. Such deep-water renewal, driven by climate gradients along the length of the lake (Boehrer and Schultze 2008), has been suggested, for example, for the East African Lake Malawi (Wüest et al. 1996; Vollmer et al. 2002) and for the deep waters of Lake Baikal (Weiss et al. 1991; Hohmann et al. 1997). Hence, the deep waters of these lakes maintain low salinity. In Lake Matano, because of its moderate size and proximity to the equator, significant climate gradients do not exist, but, in comparison to other meromictic lakes, 
such as Lake Kivu (Hutchinson 1975; Schmid et al. 2005), the salinity is low $(<0.35 \%)$. A large-scale mixing event in Lake Matano would cause the release of hypolimnetic gases and oxidation of large amounts of reduced iron and other substances hitherto trapped below the pycnocline, and could potentially lead to drastic shifts in the ecosystem. The presently observed accumulation of reduced substances, such as $\mathrm{Fe}(\mathrm{II})$ and methane, in the monimolimnion (Crowe 2008; Crowe et al. 2008b; Crowe et al., in press) suggests that such events either have not occurred in the recent past or were limited in magnitude. However, episodic mixing in the distant past cannot be ruled out. For example, evidence from fish genetics (D. Haffner unpubl. data) suggests that the ecosystem in Lake Matano is much younger ( $10,000 \mathrm{yr}$ ) than the age of the lake ( $>1$ million years). Because a large-scale mixing event may have catastrophic consequences for the Matano ecosystem, it is important to investigate the deep-water renewal regimes and estimate the present-day stability of the water column.

A numerical measure of the strength of stratification is given by stability $S$, which is defined as the work per unit area that is needed to mix the lake to a uniform temperature without adding or subtracting heat. To calculate the stability of Lake Matano, we generalize the expression of Hutchinson (1975). Neglecting the effects of the dissolved substance reactivity (Boehrer et al. 2009), the stability $S$ is equivalent to the change in potential energy due to the elevation of the lake's center of gravity:

$$
S=\frac{g}{A_{\mathrm{av}}} \int_{0}^{z_{m}} z A_{z}\left(\rho-\rho_{\text {un }}\right) d z
$$

where $g$ is the gravitational constant, $A_{\mathrm{av}}$ is the average cross-sectional area of the lake, $z_{m}$ is the maximum depth, and $A_{z}$ and $\rho$ are, respectively, the cross-sectional area and the water density at depth $z$. The uniform density after hypothetical mixing, $\rho_{\text {un }}$, is

$$
\rho_{\text {un }}=\frac{1}{V} \int_{0}^{z_{m}} \rho A_{z} d z
$$

where $V$ is the volume of the lake. By calculating the density $\rho(z)$ from typical temperature and conductivity gradients in Lake Matano (Fig. 3), we obtain $S \approx$ $200 \mathrm{~kJ} \mathrm{~m}^{-2}$. This value is one order of magnitude greater than the typical mixing energy for large and moderate meromictic lakes (Hutchinson 1975), suggesting that Lake Matano, despite its weak density gradient, is at present highly resistant to a complete overturn. The energy needed to mix the epilimnion (upper $100 \mathrm{~m}$ ), however, is only about $5 \mathrm{~kJ} \mathrm{~m}^{-2}$ (Fig. 3C), which is within the energy range that wind can deliver (Hutchinson 1975). The energy barrier to wind mixing decreases substantially during the dry season (Fig. 3C), allowing for a potentially deeper epilimnion. Using our three-dimensional hydrodynamic model, we simulated the response of Lake Matano to a brief $(24 \mathrm{~h})$ episode of strong $\left(20 \mathrm{~m} \mathrm{~s}^{-1}\right)$ winds, followed by a seiching relaxation (not shown). The results suggest that such a disturbance does not bring the persistent thermo- cline to the surface, and the monimolimnion waters do not come in contact with the atmosphere. This is in contrast with larger lakes, such as Lake Malawi, where the ratio of the wind fetch to the epilimnion depth is greater, and strong winds can bring the monimolimnion waters to the surface (T. Johnson pers. comm.). While resistant to wind mixing, Lake Matano may be still vulnerable to temperature variations. During our observation period, the temperature of the surface waters fluctuated by about $2^{\circ} \mathrm{C}$, between $27.5^{\circ} \mathrm{C}$ and $29.5^{\circ} \mathrm{C}$. Cooling of the epilimnion by a further $2^{\circ} \mathrm{C}$ to $25.5^{\circ} \mathrm{C}$, e.g., during a period of exceptionally dry weather or in response to a long-term climatic forcing, would eliminate the density gradient and allow the anoxic deep water to be mixed to the surface.

Comparison of the isotopic compositions of the Lake Matano and tributary waters (Fig. 4) constrains the possible mixing regimes and sources of the deep water. The monotonic downward progression from isotopically heavy to isotopically light waters is consistent with the monimolimnion waters being mixed with the epilimnetic waters by a spatially continuous process such as eddy diffusion. Nevertheless, unless the lake waters are becoming progressively enriched in heavier isotopes (i.e., not in steady state), mass balance requires that the downward flux of isotopically heavy water through the thermocline be balanced by the influx of isotopically light water to the monimolimnion. We hypothesize that the isotopic composition of the monimolimnion is maintained by the intrusion of ground or tributary waters. At the measured temperatures of $21.8-23^{\circ} \mathrm{C}$, the tributary waters are colder and, therefore, denser than the epilimnetic waters $\left(27.5-29.1^{\circ} \mathrm{C}\right)$, but hydrodynamic simulations suggest that the tributary waters are unlikely to reach below the persistent pycnocline. Simulated dispersion of a tracer released at the mouth of the largest Matano inflow, La (River) Wa, indicates that, because of the exchange of heat and mixing with the surrounding waters, the river waters flow into the middleto-lower epilimnion (Fig. 6B). The simulations did not consider density effects associated with the suspended sediment, which is minimal in the tributaries except after strong rainfall events. In contrast to tributary waters, cold groundwaters can penetrate underneath the pycnocline directly, along the steep walls of the lake basin. Based on the downward mixing rates defined by the $K_{z}$ values in Fig. 5A, the required steady-state influx of isotopically light water to the monimolimnion of Lake Matano is on the order of $10 \mathrm{~m}^{3} \mathrm{~s}^{-1}$. At this rate, the minimum time for renewal of monimolimnion water is $130 \mathrm{yr}$.

The presence of slightly isotopically heavier waters below $500 \mathrm{~m}$ (Fig. 4) is enigmatic and may indicate the influx of surface waters (but not groundwaters or river waters) through density flows caused by sediment slumping. While plausible, given the abundant sediment slumping along the steep slopes of Lake Matano, this hypothesis is not supported by the vertical distributions of major cations, such as $\mathrm{Ba}, \mathrm{Mg}$, and $\mathrm{Ca}$, which do not display a similar feature in the deep water (Crowe 2008).

The timescale of the vertical heat and water exchangeThe persistence of a temperature gradient below the mixed layer in the depth interval $100-300 \mathrm{~m}$ implies diffusion of 
Lake Matano mixing and biogeochemistry

Table 4. Biogeochemical model reactions.

\begin{tabular}{llrrrr}
\hline \hline \multirow{2}{*}{ Reaction } & & \multicolumn{3}{c}{ Stoichiometry } \\
\cline { 2 - 5 } & \multicolumn{1}{c}{ Rate law } & $\mathrm{O}_{2}$ & $\mathrm{Fe}(\mathrm{II})$ & $\mathrm{CH}_{4}$ & Depth interval (m) \\
\hline Consumption of $\mathrm{O}_{2}$ & $k_{\mathrm{O}_{2}}\left[\mathrm{O}_{2}\right]$ & -1 & 0 & 0 & $>100$ \\
Oxidation of $\mathrm{Fe}(\mathrm{II})$ & $k_{\mathrm{FeOx}}[\mathrm{Fe}(\mathrm{II})]$ & 0 & -1 & 0 & $<110$ \\
Oxidation of $\mathrm{CH}_{4}$ & $k_{\mathrm{CH}_{4} \mathrm{Ox}}\left[\mathrm{CH}_{4}\right]$ & 0 & 0 & -1 & $<103$ \\
\hline
\end{tabular}

heat from the mixed epilimnion to the deep waters. Conservation of energy necessitates a heat sink at the bottom, or the temperature in the deep waters would increase. Based on the temperature gradient in Fig. 3A and the $K_{z}(z)$ in Fig. 5A, the downward heat flux in Lake Matano is approximately $0.2 \mathrm{~W} \mathrm{~m}^{-2}$. (For comparison, the expected upward flux of the geothermal heat in Sulawesi is $0.050 \mathrm{~W} \mathrm{~m}^{-2}$.) In the absence of a monimolimnetic heat sink, the downward heat flux would increase the deepwater temperatures by approximately $0.006^{\circ} \mathrm{C} \mathrm{yr}^{-1}$. This rate is within the detection limit of modern instruments and can be verified in future studies. The rate is small enough for the lake to be in a quasi-steady state over many decades: it would take $\sim 600 \mathrm{yr}$ to eliminate the present temperature gradient. Heat can also be dissipated to the monimolimnion sediments and/or groundwater intrusions, which would have to be colder than the bottom waters $\left(25.5^{\circ} \mathrm{C}\right)$. To absorb the downward heat flux of $0.2 \mathrm{~W} \mathrm{~m}^{-2}$, groundwaters having a temperature of $21^{\circ} \mathrm{C}$ would need to be supplied at a rate of only $1.3 \mathrm{~m}^{3} \mathrm{~s}^{-1}$. This is small enough to be undetectable in the temperature profiles in Fig. 3A. Renewal of the monimolimnion water at this rate would occur in $\sim 1000 \mathrm{yr}$.

Several other lines of evidence also suggest a timescale of 200-1000 yr for renewal of the monimolimnion waters, which is at least one order of magnitude slower than in Lake Malawi (15-18 yr) and Lake Baikal (10-18 yr) (Weiss et al. 1991; Ravens et al. 2000). Using $K_{z}=0.45 \mathrm{~m}^{2} \mathrm{~s}^{-1}$ in the order-of-magnitude expression of Imboden and Wüest (1995), Crowe et al. (2008a) estimated that the renewal time of the bottom waters was $200 \mathrm{yr}$ or longer. Radiocarbon $\left({ }^{14} \mathrm{C}_{\mathrm{CH}_{4}}\right)$ dating (Crowe 2008; Crowe et al., in press) of the biogenic $\left(\delta^{13} \mathrm{C}=-72 \%\right.$ o $)$ methane in the monimolimnion indicates that methane carbon contains $77.4 \pm 0.2$ percent modern carbon (pMC) (Stuiver and Polach 1977) in the transition zone (depths 105-200 m), and 75.0 $\pm 0.1 \mathrm{pMC}$ in the deep water ( $>250-\mathrm{m}$ depth). This corresponds to a maximum carbon age of $2050 \mathrm{yr}$ in the transition zone and $2300 \mathrm{yr}$ in the deep waters. With the reservoir correction being unknown (but correcting toward younger methane ages), and provided that the methane is released from the sediments by organic matter mineralization within a thousand years after deposition, the residence time of methane in the monimolimnion is between several hundred and $1000 \mathrm{yr}$. This figure is consistent with the rates at which biogenic methane can be supplied from the sediments of Lake Matano: based on the rates of methane oxidation at the thermocline, as well as on the rates of organic matter sedimentation, Crowe (2008) estimated the sediment efflux of methane at $3.6 \mathrm{mmol} \mathrm{m}-2 \mathrm{~d}^{-1}$. Simulations using a biogeochemical model (see below) indicate that, at this rate, following a hypothetical complete mixing event, methane concentrations in the monimolimnion would require approximately $600 \mathrm{yr}$ to reach their present values. Similarly, dissolved Fe(II) would reach its present concentration in approximately $250 \mathrm{yr}$. These estimates allow for the possibility that the biogeochemical cycles in the lake have yet to reach a steady state (e.g., after a hypothetical mixing event within the last millennium), but they indicate that it is highly unlikely that the deep waters are renewed on a shorter (e.g., decadal) timescale.

Biogeochemical cycling-The spatial distributions of solutes in the water columns of stratified lakes are shaped by the interplay of biogeochemical reactions and transport processes. These complex interactions and the in situ reaction rates are routinely interpreted with the help of reaction-transport models (Taillefert and Gaillard 2002; Katsev et al. 2006, 2007). In these models, the transport of substances is commonly described, for lack of information, by transport coefficients that are constant in space. With the information we now have about the vertical distribution of $K_{z}$ in Lake Matano (Fig. 5a), we can avoid making this simplification and thus obtain a better understanding of the role that physical transport plays in biogeochemical cycling. Our reaction-transport model was implemented in AQUASIM (Reichert 1998), and parameterizations are shown in Tables 4 and 5. The vertical variation in the rates of turbulent diffusion was specified explicitly: we used a 20m running average of the $K_{z}$ profile obtained from the analysis of Thorpe instabilities (Fig. 5A).

The results of our simulations do not conform to the conventionally made assumption that vertical gradients in the concentrations of chemical species vary with depth as a result of the species consumption or production through bulk reactions. In Lake Matano, outside of the narrow

Table 5. Biogeochemical model parameters.

\begin{tabular}{lll}
\hline \hline \multicolumn{1}{c}{ Parameter } & Value & \multicolumn{1}{c}{ Unit } \\
\hline Sediment efflux of $\mathrm{CH}_{4}$ & 3.7 & $\mathrm{mmol} \mathrm{m}^{-2} \mathrm{~d}^{-1}$ \\
Sediment efflux of $\mathrm{Fe}(\mathrm{II})$ & 0.45 & $\mathrm{mmol} \mathrm{m}^{-2} \mathrm{~d}^{-1}$ \\
$\mathrm{O}_{2}$ concentration at lake surface & 0.25 & $\mathrm{mmol} \mathrm{L}^{-1}$ \\
$k_{\mathrm{O}_{2}}$ & $10^{4}$ & $\mathrm{~d}^{-1}$ \\
$k_{\mathrm{FeOx}}$ & $3 \times 10^{7}$ & $\mathrm{~d}^{-1}$ \\
$k_{\mathrm{CH}} \mathrm{Ox}$ & $3 \times 10^{6}$ & $\mathrm{~d}^{-1}$ \\
\hline
\end{tabular}




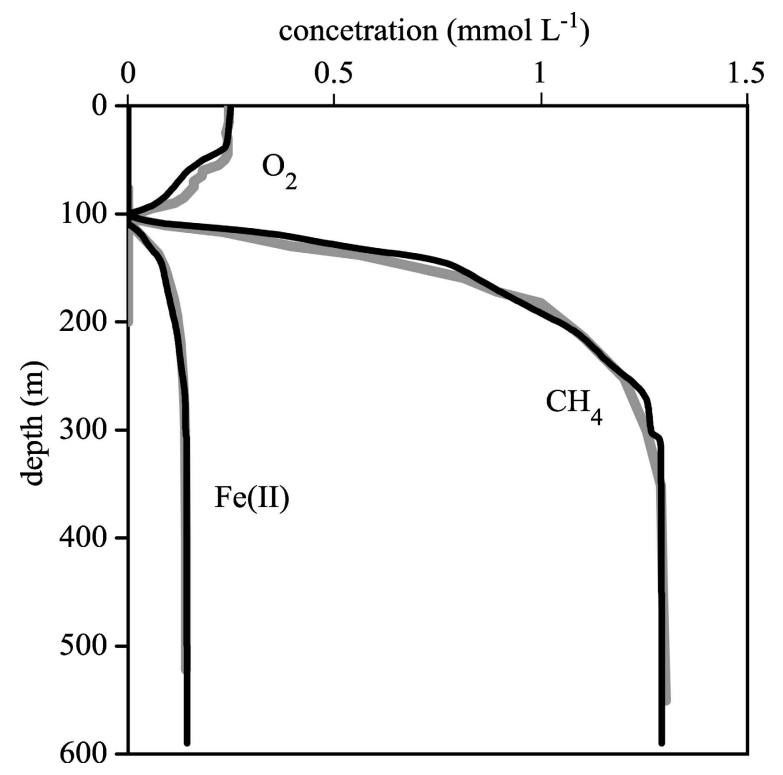

Fig. 8. Simulated (black) and measured (gray) profiles of dissolved oxygen, iron, and methane. Simulations used $K_{z}$ from Fig. 5A and assumed no bulk reactions in the water column, except at the redoxcline. Measured data are from Crowe (2008) and Crowe et al. (2008a).

chemocline region around $100-\mathrm{m}$ depth, the vertical concentration gradients of most species are shaped almost exclusively by depth variations in $K_{z}$. As illustrated in Fig. 8, the observed profiles of dissolved $\mathrm{O}_{2}, \mathrm{Fe}(\mathrm{II})$, and $\mathrm{CH}_{4}$ are reproduced by a very simple model: reactive species are supplied only from the surface $\left(\mathrm{O}_{2}\right)$ or from the sediments $\left(\mathrm{Fe}(\mathrm{II})\right.$ and $\mathrm{CH}_{4}$ ) (Table 5) and consumed by redox reactions only at the persistent thermocline, between 100 and $110 \mathrm{~m}$ (Table 4). No chemical reactions need to be considered anywhere else in the water column. To better illustrate this point, model reactions were intentionally decoupled from each other (Table 4), with the reaction rate constants (Table 5) being sufficiently large to ensure consumption of the species within the thermocline; model solutions were insensitive to their values. Under this approximation, a mixing rate that does not vary with depth (i.e., $K_{z}(z)=$ const), would have resulted in linear profiles. Our results in Fig. 8 show that virtually all changes in the concentration gradients (i.e., curvature in the profiles) can be attributed to variations in the vertical diffusivity, $K_{z}$. Of course, this does not mean that chemical reactions do not occur outside of the thermocline, but it reveals that the rates at which these chemical species are produced or consumed in the water column are much smaller than their rates of vertical transport. The fact that chemical gradients are shaped by the depth variations in $K_{z}$ makes it impossible to use the vertical distributions of chemical substances to estimate mixing rates. That physical mixing determines the distribution of solutes in the water column is further illustrated in Fig. 9: below the pycnocline, the vertical distributions of stable oxygen isotopes, dissolved iron, phosphate, methane, and major cations $(\mathrm{Ca}$ and $\mathrm{Mg}$, not shown) (Crowe et al. 2008a) all coincide with

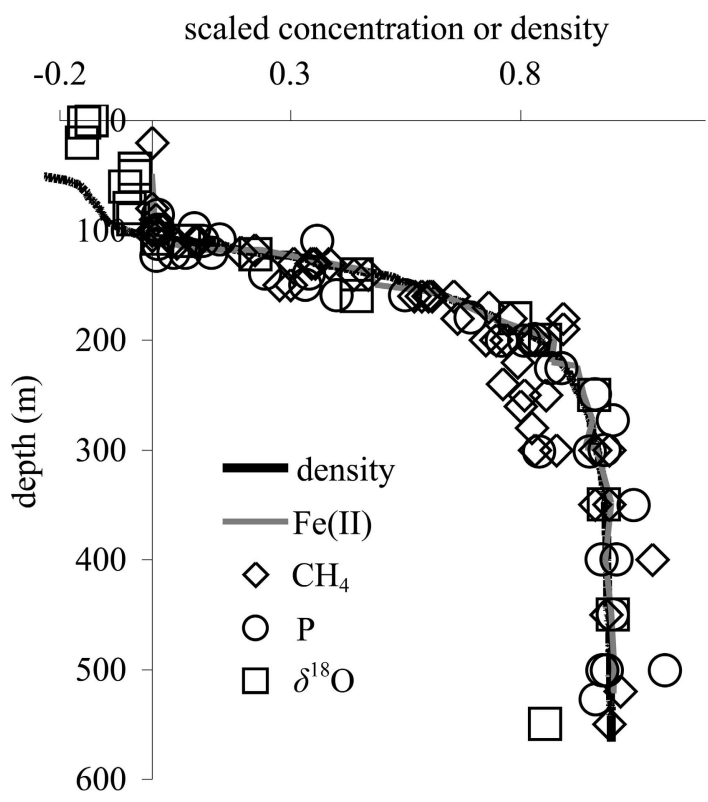

Fig. 9. The profiles of dissolved iron, methane, phosphorus, and $\delta^{18} \mathrm{O}$ superposed on the water density profile. The concentrations and density are scaled as $(X-A) /(B-A)$, where $A$ and $B$ are values of the corresponding quantity $X$ at the thermocline and in the deep waters, respectively. Data are from Crowe (2008) and Crowe et al. (2008a).

the shape of the physical density profile. Under steady state, in the absence of reactions, the diffusive flux of an element with concentration $C(z)$ is constant with depth:

$$
A_{z}(z) K_{z}(z) \frac{\partial C}{\partial z}=\text { const }
$$

where $A_{z}$ is the areal cross section of the lake at depth $z$. The similarity of the gradients $\partial C / \partial z$ for several different elements indicates that these are shaped by the common term $A_{z}(z) K_{z}(z)$ rather than by geochemical sources or sinks in the water column. The agreement between the shapes of the measured and simulated profiles (the latter obtained using $K_{z}(z)$ in Fig. 5A), in turn, lends credibility to the $K_{z}(z)$ profile in Fig. 5A. The elements whose profile shapes are different from those in Fig. 9, such as $\mathrm{Mn}$ and $\mathrm{Ni}$ (Crowe et al. 2008a), must participate in biogeochemical reactions that have markedly different depth dependencies and proceed at rates exceeding those of physical transport.

\section{Acknowledgments}

S.K. is thankful to Ilia Ostrovsky, Maria Dittrich, Daniel McGinnis, and Nigel Wattrus for fruitful discussions, and to Matthew Hipsey and Ursula Salmon for help with ELCOM. The work was supported by the University of Minnesota Duluth startup funds to the lead author and the University of Minnesota Grant-in-Aid. Data acquisition was made possible through funding by Inco Canada Ltd. and Perseroan Terbatas Inco Terbuka, through a Natural Sciences and Engineering Research Council of Canada (NSERC) Industrial Partnership Scholarship to S.A.C.; Discovery grants to A.M., B.S., and D.H.; and the University of Kansas Geology Associates support to D.A.F. 


\section{References}

Aeschbach-Hertig, W., C. P. Holzner, M. Hofer, M. Simona, A. Barbieri, AND R. Kipfer. 2007. A time series of environmental tracer data from deep, meromictic Lake Lugano, Switzerland. Limnol. Oceanogr. 52: 257-273.

Amorocho, J., AND J. DE VRies. 1980. A new evaluation of the wind stress coefficient over water surface. J. Geophys. Res. 85: 433-442.

Araguás-Araguás, L., K. Froehlich, and K. Rozanski. 1998. Stable isotope composition of precipitation over southeast Asia. J. Geophys. Res. 103: 28721-28742.

Beal, E. J., C. H. House, and V. J. Orphan. 2009. Manganese and iron dependent marine methane oxidation. Science 325: 184-187.

Boehrer, B., S. Dietz, C. von Rohden, U. Kiwel, K. D. Jöhnk, S. Naujoks, J. Ilmberger, and D. Lessmann. 2009. Doublediffusive deep water circulation in an iron-meromictic lake. Geochem. Geophys. Geosyst. 10: Q06006, doi:10.1029/ 2009GC002389.

- R. Fukuyama, and K. Chikita. 2008. Stratification of very deep, thermally stratified lakes. Geophys. Res. Lett. 35: L16405: doi: 10.1029/2008GL034519.

—, And M. Schultze. 2008. Stratification of lakes. Rev. Geophys. 46: 210-236.

Chen, C. T., And F. J. Millero. 1986. Precise thermodynamic properties for natural waters covering only the limnological range. Limnol. Oceanogr. 31: 657-662.

Craig, H. 1961. Isotopic variations in meteoric waters. Science 133: $1702-1703$.

Crawford, G. B., and R. W. Collier. 2007. Long-term observations of deepwater renewal in Crater Lake, Oregon. Hydrobiologia 574: 47-68.

Crowe, S. A. 2008. Biogeochemical cycling in iron-rich Lake Matano, Indonesia: An early ocean analogue. Ph.D. thesis. McGill Univ.

—, A. H. O’Neill, S. Katsev, P. Hehanussa, G. D. Haffner, B. Sundby, A. Mucci, And D. A. Fowle. $2008 a$. The biogeochemistry of tropical lakes: A case study from ancient Lake Matano, Indonesia. Limnol. Oceanogr. 53: 319-331.

- AND OTHERs. 2008b. Deep water photoferrotrophs thrive in an Archean ocean analogue. Proc. Natl. Acad. Sci. 105: $15938-15943$.

- AND OTHERS. In press. The methane cycle in ferruginous Lake Matano. Geobiology.

Dillon, T. M. 1982. Vertical overturns: A comparison of Thorpe and Ozmidov length scales. J. Geophys. Res. 87: 9601-9613.

GAt, J. R. 1996. Oxygen and hydrogen isotopes in the hydrological cycle. Annu. Rev. Earth Planet. Sci. 24: 225-262.

Hodges, B., And C. Dallimore. 2007. Estuary, lake and coastal ocean model: ELCOM, v2.2 user manual. Centre for Water Research, Univ. Western Australia.

Hohmann, R., R. Kipfer, F. Peeters, G. Piepke, and D. M. ImbodEN. 1997. Processes of deep-water renewal in Lake Baikal. Limnol. Oceanogr. 42: 841-855.

Horn, D. A., J. Imberger, And G. N. Ivey. 2001. The degeneration of large-scale interfacial gravity waves in lakes. J. Fluid Mech. 434: 181-207.

Hutchinson, G. E. 1975. A treatise on limnology: Geography and physics of lakes. Wiley.

Imboden, D. M., And A. Wüest. 1995. Mixing mechanisms in lakes, p. 83-138. In A. Lerman, D. Imboden, and J. Gat [eds.], Physics and chemistry of lakes. Springer-Verlag.
JAssby, A., AND T. Powell. 1975. Vertical patterns of eddy diffusion during stratification of Castle Lake, California. Limnol. Oceanogr. 20: 530-543.

Jellison, R., And J. M. Melack. 1993. Meromixis in hypersaline Mono Lake, California. 1. Stratification and vertical mixing during the onset, persistence, and breakdown of meromixis. Limnol. Oceanogr. 38: 1008-1019.

Katsev, S., G. Chaillou, B. Sundby, and A. Mucci. 2007. Effect of progressive oxygen depletion on sediment diagenesis and fluxes: A model for the Lower St. Lawrence Estuary. Limnol. Oceanogr. 52: 2555-2568.

—- AND I. L'Heureux. 2002. Autocatalytic model of oscillatory zoning in experimentally grown $(\mathrm{Ba}, \mathrm{Sr}) \mathrm{SO}_{4}$ solid solution. Phys. Rev. E 66: 066206.

, I. Tsandev, I. L'Heureux, and D. G. Rancourt. 2006. Factors controlling long term phosphorus efflux in lake sediments: Exploratory reaction-transport modeling. Chem. Geol. 234: 127-147.

Killworth, P. D., E. C. Carmack, R. F. Weiss, and R. Matear. 1996. Modeling deep-water renewal in Lake Baikal. Limnol. Oceanogr. 41: 1521-1538.

Lerman, A. 1979. Geochemical processes water and sediment environments. Wiley.

Lewis, W. M. 1982. Vertical eddy diffusivities in a large tropical lake. Limnol Oceanogr. 27: 161-163.

. 1987. Tropical limnology. Annu. Rev. Ecol. Syst. 18: 159-184.

Lorke, A., AND A. WüEst. 2005. Turbulence and mixing regimes specific to lakes, p. 346-354. In H. Z. Baumert, J. Simpson, and J. Sündermann [eds.], Marine turbulence-theories, observations and models. Cambridge Univ. Press.

Peeters, F., G. Piepke, R. Kipfer, R. Hohmann, and D. M. IMBODEN. 1996. Description of stability and neutrally buoyant transport in freshwater lakes. Limnol. Oceanogr. 41: 17111724.

Quay, P. D., W. S. Broecker, R. H. Hesslein, and D. W. SCHINDLER. 1980. Vertical diffusion rates determined by tritium tracer experiments in the thermocline and hypolimnion of two lakes. Limnol. Oceanogr. 25: 201-218.

Ravens, T. M., O. Kocsis, A. Wüest, and N. Granin. 2000. Small-scale turbulence and vertical mixing in Lake Baikal. Limnol. Oceanogr. 45: 159-173.

ReIchert, P. 1994. AQUASIM-a tool for simulation and data analysis of aquatic systems. Water Sci. Technol. 30: 21-30.

-1998. AQUASIM 2.0 user manual. EAWAG.

Rohden, C., AND J. Ilmberger. 2001. Tracer experiment with sulfur hexafluoride to quantify the vertical transport in a meromictic pit lake. Aquat. Sci. 63: 417-431.

Rozanski, K., L. Araguás-Araguás, and R. Gonfiantini. 1993. Isotopic patters in modern global precipitation, p. 1-36. In P. K. Swart, K. L. Lohmann, J. McKenzie, and S. Savin [eds.], Climate change in continental isotopic records, Geophys. Monogr. Ser., 78, Am. Geophys. Union.

Schmid, M., M. Halbwachs, B. Wehrli, and A. Wüest. 2005. Weak mixing in Lake Kivu: New insights indicate increasing risk of uncontrolled gas eruption. Geochem. Geophys. Geosyst. 6: Q07009, doi:10.1029/2004GC000892.

Stuiver, M., And H. A. Polach. 1977. Reporting of C-14 datadiscussion. Radiocarbon 19: 355-363.

TAillefert, M., and J. F. Gaillard. 2002. Reactive transport modeling of trace elements in the water column of a stratified lake: Iron cycling and metal scavenging. J. Hydrol. 256: 16-34.

Thorpe, S. A., And A. J. Hall. 1977. Mixing in upper layer of a lake during heating cycle. Nature 265: 719-722. 
Varekamp, J. C., and R. Kreulen. 2000. The stable isotope geochemistry of volcanic lakes, with examples from Indonesia. J. Volcanol. Geothermal Res. 97: 309-327.

Vollmer, M. K., R. F. Weiss, and H. A. Bootsma. 2002. Ventilation of Lake Malawi/Nyasa, p. 209-233. In E. O. Odada and D. O. Olago [eds.], The East African Great Lakes: Limnology, paleolimnology and biodiversity. Advances in Global Change Research. Kluwer Academic Publishers.

Weiss, R. F., E. C. Carmack, and V. M. Koropalov. 1991. Deepwater renewal and biological production in Lake Baikal. Nature 349: 665-669.

Welander, P. 1968. Theoretical forms for the vertical exchange coefficients in a stratified fluid with application to lakes and seas. Acta R. Sot. Sci. Litt. Gothob. Geophys. 1: 1-26.
Wüest, A., G. Piepke, and J. D. Halfman. 1996. Combined effects of dissolved solids and temperature on the density stratification of Lake Malawi, p. 183-202. In T. C. Johnson and E. O. Odada [eds.], The limnology, climatology and paleoclimatology of the East African Lakes, 1st ed. Gordon and Breach.

Associate editor: Chris Rehmann

Received: 30 July 2009

Accepted: 24 September 2009 Amended: 03 December 2009 